\title{
Childhood abuse increases the risk of depressive and anxiety symptoms and history of suicidal behavior in Mexican pregnant women
}

\author{
Ma. Asunción Lara, ${ }^{1}$ Laura Navarrete, ${ }^{1}$ Lourdes Nieto, ${ }^{1}$ Huynh-Nhu Le ${ }^{2}$ \\ ${ }^{1}$ Instituto Nacional de Psiquiatría Ramón de la Fuente Muñiz, Ciudad de México, DF, Mexico. ${ }^{2}$ Department of Psychology, George Washington \\ University, Washington, DC, USA.
}

\begin{abstract}
Objective: To explore the relationship between individual and co-occurring childhood sexual, physical, and verbal abuse, prenatal depressive (PDS) and anxiety symptoms (PAS), and history of suicidal behavior (HSB) among Mexican pregnant women at risk of depression.

Methods: A sample of 357 women screened for PDS was interviewed using the Childhood Experience of Care and Abuse Questionnaire (CECA-Q), the Beck Depression Inventory (BDI-II), the anxiety subscale of the Hopkins Symptoms Checklist (SCL-90), and specific questions on verbal abuse and HSB.

Results: Logistic regression analyses showed that women who had experienced childhood sexual abuse (CSA) were 2.60 times more likely to develop PDS, 2.58 times more likely to develop PAS, and 3.71 times more likely to have HSB. Childhood physical abuse (CPA) increased the risk of PAS (odds ratio $[O R]=2.51)$ and HSB $(O R=2.62)$, while childhood verbal abuse $(C V A)$ increased PDS $(\mathrm{OR}=1.92)$. Experiencing multiple abuses increased the risk of PDS $(\mathrm{OR}=3.01)$, PAS $(\mathrm{OR}=3.73)$, and HSB (OR = 13.73).

Conclusions: Childhood sexual, physical, and verbal abuse, especially when they co-occur, have an impact on PDS and PAS and lifetime HSB. These findings suggest that pregnant women at risk for depression should also be screened for trauma as a risk factor for perinatal psychopathology.
\end{abstract}

Keywords: Child abuse; pregnancy; prenatal depression; prenatal anxiety; suicide

\section{Introduction}

It is well documented that individuals abused as children experience a variety of psychological problems, including depression, anxiety, and suicide attempts. ${ }^{1-3}$ Early adverse experiences, in concert with hereditable factors, alter brain and behavior (cognition, emotional regulation, social interaction styles) of children at a young age. ${ }^{2}$ According to Grassi-Oliveira et al., ${ }^{4}$ child abuse can be perceived as an agent for neurodevelopmental disruption and, depending on when it occurs, may cause serious neurological "scars" in certain structures, which may make some individuals vulnerable to certain types of psychopathology.

Pregnancy can be particularly challenging for women who were victims of childhood abuse. Pregnancy is a time of stress requiring new or enhanced coping skills. During this period, women experience many physical changes, such as sensations of the fetus moving within their bodies or frequent pelvic examinations, which may be more difficult for those who have experienced abuse. ${ }^{5}$ Furthermore, pregnant women are at increased risk of psychopathology, and those with a history of abuse may be particularly vulnerable. ${ }^{6}$

Correspondence: Ma. Asunción Lara, Ramón de la Fuente, National Institute of Psychiatry, Calzada México-Xochimilco, 101, San Lorenzo Huipulco, 14370, Tlalpan, DF, Mexico.

E-mail: laracan@imp.edu.mx

Submitted May 27 2014, accepted Nov 042014.
Research has examined the relationship between a history of childhood abuse and psychopathology during pregnancy. As a whole, this work has found that having a history of childhood physical abuse (CPA) and/or sexual abuse (CSA) is related to suicidal ideation and/or suicide attempts during pregnancy. ${ }^{1,7}$ However, findings have been mixed regarding the relationship between childhood abuse and increased risk of prenatal depression or anxiety. Leeners et al. ${ }^{6}$ conducted a systematic literature review in 2006 and concluded that pregnant women with a history of CSA were more likely to experience depression and anxiety. However, subsequent studies yielded conflicting findings. While some studies found a history of CSA and/or CPA to be associated with depression during pregnancy, ${ }^{7-10}$ others have failed to detect a link. ${ }^{11,12}$ To our knowledge, only one study examined the effect of a history of childhood verbal abuse (CVA), but did not find significant associations with depression. ${ }^{9}$ Overall, the emerging evidence suggests that, with some exceptions, ${ }^{11,12}$ a history of abuse, particularly sexual and physical ${ }^{8-10}$ but not $\mathrm{CVA}^{9}{ }^{9}$ is associated with several negative mental health consequences in pregnant women. ${ }^{6,8-9}$

Psychopathology during pregnancy is of particular importance because it has well-documented negative health effects on both mother and child. Depression during pregnancy adversely affects eating habits, which, in turn, leads to poor prenatal care; depression in this period also increases a woman's risk for postpartum 
depression. ${ }^{13}$ Prenatal depression has been associated with premature birth and low birth weight. ${ }^{13}$ Anxiety during pregnancy is associated with prematurity, ${ }^{14}$ while suicide attempts during pregnancy are associated with higher rates of maternal and perinatal morbidity and, in some cases, with perinatal mortality. ${ }^{15}$

In short, there is a need for further studies on whether pregnant women with a history of CSA, CPA, and/or CVA are at increased risk of psychopathology. Such research has important implications for the health of both women and children. Additionally, there is a dearth of research in Latin America on the relationship between a woman's prior experience of childhood abuse and perinatal psychopathology. We found no such studies conducted in Latin America, despite the fact that an estimated $12.3 \%$ of Mexican women report clinical depression during pregnancy ${ }^{16}$ and $23.3 \%$ of Brazilian women reported significant depressive symptoms during this period. ${ }^{17}$

The aim of this secondary data analysis is to explore the relationship between CPA, CSA, or CVA and prenatal depressive symptoms (PDS), prenatal anxiety symptoms (PAS), and a history of suicidal behavior (HSB) in a sample of Mexican pregnant women at risk of depression. It should be noted that suicidal behavior during pregnancy was not our outcome variable, because women with a suicide attempt in the past 6 months were excluded from the primary randomized controlled trial (RCT) and referred to treatment for ethical reasons. Nevertheless, this sample provides an opportunity to study the effects of the experiences of trauma in women who were screened for depressive symptoms, as studies often find that women with depression tend to report higher rates of sexual abuse than their non-depressed counterparts. ${ }^{18}$ The effect of abuse is studied within the context of the type(s) of abuse and mediating (social support, partner relationship quality, and history of depression) and confounding (marital status, income, and education) factors. There is evidence that these factors are related to an increased risk of depressive symptoms during pregnancy. $^{19}$

\section{Methods}

\section{Sample}

This study is based on secondary analysis of data collected as part of an RCT evaluating a psychoeducational intervention to prevent postpartum depression. ${ }^{20}$ In the primary study, a convenience sample was drawn from pregnant women seeking attention at three health facilities in Mexico City: 1) a hospital setting that provides care for women with high-risk pregnancies; 2) a women's clinic that provides obstetric and gynecological services for women in the Armed Forces as well as for the wives of men in the Armed Forces; and 3) a community health care center providing prenatal care and other comprehensive medical care for local women. The inclusion criteria were: 1) pregnant women aged over 18 years; 2) up to 26 weeks of gestation; 3) at least a minimum reading ability (having completed primary school); 4) living in the
Metropolitan area of Mexico City; 5) no indication of bipolar disorder, substance abuse, or reported suicide attempts during the previous 6 months; and 6) high depressive symptomatology (score $\geqslant 16$ on the Center for Epidemiological Studies Depression Scale [CES-D] ${ }^{21}$ and/or previous history of depression, but not currently in psychological/psychiatric treatment) (Figure 1). Three hundred and fifty-seven women completed baseline information and were therefore included in this secondary analysis. No additional data were collected for these analyses. Interviews were conducted by trained psychologists from the research team in the waiting rooms of the institutions. The original study was approved by the Institutional Review Board of the Ramón de la Fuente National Institute of Psychiatry.

\section{Instruments}

\section{Sociodemographic data}

The variables included in the study were: age, education, family income, and partner status (with partner: married or living with partner; without partner: single, divorced, or widowed).

\section{Abuse}

CSA was measured using three questions from the Childhood Experience of Care and Abuse Questionnaire $(C E C A-Q)^{22}$ : 1) When you were a child or teenager did you ever have any unwanted sexual experiences?; 2) Did anyone force you or persuade you to have sexual intercourse against your wishes before age 17?; and 3) Can you think of any upsetting sexual experiences before age 17 with a related adult or someone in authority, e.g., a teacher? A positive answer to any one of these questions (yes/no) was indicative of CSA. Severity was defined ${ }^{22}$ as a positive response to any of the following situations: the perpetrator was a) someone she knew, b) a relative, or c) a member of her household, or the incident(s) described involved d) more than one encounter, e) the touching of her private parts, $f$ ) the participant being forced to touch the perpetrator's private parts, or g) sexual intercourse. CPA was also measured using one of the CECA-Q questions: When you were a child or teenager were you ever hit repeatedly with an implement (such as a belt or a stick) or punched, kicked, or burnt by someone in the household? A positive answer to this question (yes/no) was indicative of CPA. CVA was measured after abuse studies ${ }^{23,24}$ using a similar format to CPA: When you were a child or teenager were you ever threatened or insulted by someone in the household? and added: Did it occur very frequently? A positive answer (yes/no) to both questions was indicative of CVA. Similar abuse questions were used in a previous study with Mexican women at risk of depression, which resulted in an efficient measure of CSA, CPA, and CVA for this population. ${ }^{18}$

\section{Depressive symptoms}

The Beck Depression Inventory, Second Edition (BDI-II) ${ }^{25}$ evaluates depressive symptoms for the 2 weeks prior to 


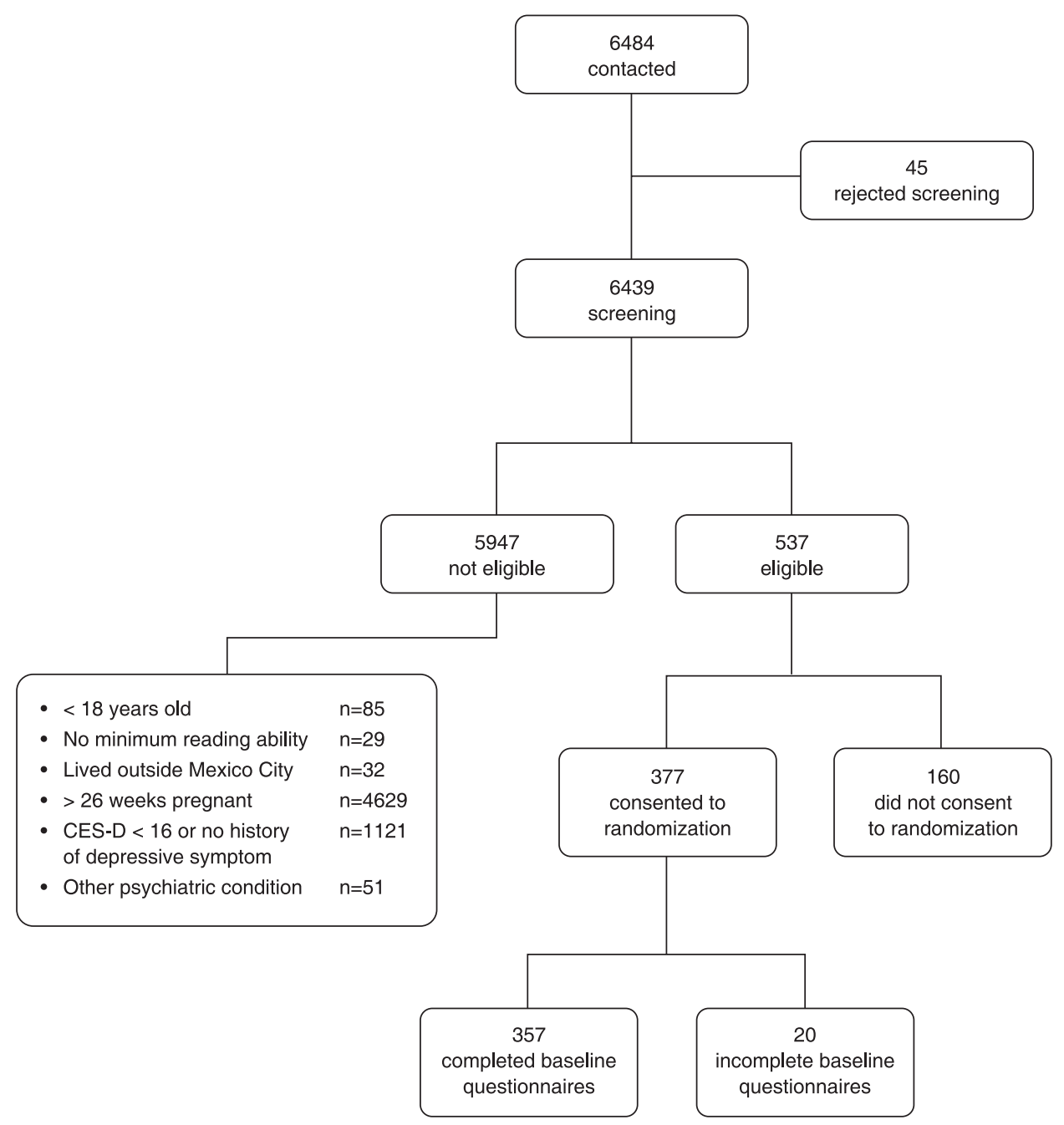

Figure 1 Recruitment of study participants.

its administration. It consists of 21 items scored on a four-point scale ranging from 0 to 3 . The cutoff score is 14 ; thus, a BDI-II $>14$ indicates a high risk of clinical depression. $^{25}$ In Mexico, one study found that the reliability of this measure was excellent (Cronbach's $\alpha=0.87){ }^{26}$

\section{History of depression}

This aspect was assessed by the mood disorders module of the Structured Clinical Interview (SCID) ${ }^{27}$ based on the DSM-IV criteria.

\section{Anxiety symptoms}

The study used the anxiety subscale of the Hopkins Symptoms Checklist (SCL-90) to measure anxiety symptoms. $^{28}$ This 10-item scale evaluates the degree of unease felt within the past 2 weeks on a five-point Likert scale (none $=0$; extreme $=4$ ). Its internal consistency in the Mexican population is moderate (Cronbach's $\alpha=0.80) .{ }^{29}$ A score of $>18$ is considered an indicator of high anxiety symptomatology. ${ }^{28}$
History of suicidal behavior

This construct was measured using questions from both Medina-Mora et al. ${ }^{30}$ and Gonzalez-Forteza et al. ${ }^{31}$ The questions on this topic were: Have you ever been about to take your own life ${ }^{30}$ and Have you ever intentionally hurt, cut, poisoned, or harmed yourself in order to take your own life ${ }^{31}$ The percentage of women responding affirmatively to these questions was $24.1 \%$ and $17.1 \%$, respectively. HSB was defined as an affirmative answer to either of the above questions.

\section{Social support}

This variable was measured using the Social Support Apgar (SSA) ${ }^{32}$ scale, which assesses the woman's perceptions of and satisfaction with various sources of support. The scale consists of 30 questions with responses indicating degree of satisfaction ( 1 = almost never; 2 = sometimes; 3 = almost always). The Spanish version, evaluated with Latino women who live in the United States, demonstrated excellent internal consistency (Cronbach's $\alpha=0.94) .{ }^{33}$ Since the scale had not previously been used 
in Mexico, its internal consistency was estimated for this same sample and was also excellent (Cronbach's $\alpha=0.90$ at 6 weeks and $\alpha=0.91$ at $4-6$ months postpartum). The cutoff score $<20$ reflects a low level of satisfaction with one's social support. ${ }^{32}$

Partner relationship quality

This variable was measured using the Abbreviated Version of Dyadic Adjustment Scale (A-DAS). This instrument consists of seven of the original 32 items developed by Spanier. ${ }^{34}$ The combined score ranges from 0-30, with higher scores indicating greater levels of marital/partner adjustment. The A-DAS has been found to have good psychometric properties among ethnic minorities, including Latinos. Modeled after the work of Sharpley and Cross, a cutoff point of $<15$ was used to indicate a low level of relationship quality. ${ }^{35}$

\section{Overview of data analyses}

Frequencies were calculated for categorical variables and means, medians, and standard deviations for continuous variables. Three logistic regression analyses were conducted to assess the impact of CSA, CPA, and CVA on each dependent variable: PDS, PAS, and HSB. These analyses yielded maximum likelihood estimates for combined relative odds with $95 \%$ confidence intervals $(95 \% \mathrm{Cl})$. Additional logistic regressions were conducted to adjust for confounding (partner status, income, and education) and mediating (history of major depression, partner relationship quality, and social support) factors. Age was not included in the model because it is not a significant predictor of the dependent variables, according to a literature review ${ }^{18}$; age was also not significantly correlated with the abuse variables in the present study (with CSA, $r=0.04$; with CPA, $r=0.04$; with CVA, $r=0.02)$. Partner status, income, and education were not significantly related to dependent variables in this study, but were included because they have been shown to be significant predictors in other studies. ${ }^{18}$

Before conducting the logistic regression analyses, a correlation matrix was constructed to assess the strength and direction of the relationship between the variables using point-biserial correlations.

Three additional logistic regression analyses assessed the impact of the number of abuses on psychopathology, adjusting for the same mediating and confounding factors. The independent variable number of abuses was constructed by adding each independent type of abuse (CSA, CPA, CVA). Analyses were conducted using STATA software version 11 .

\section{Results}

Mean age was $27.05 \pm 5.98$ years, with $11.39 \pm 3.11$ years of education and a monthly income of $\$ 5457.96 \pm 4490.50$ pesos (13 pesos equals approximately one U.S. dollar). The vast majority of participants, $86.6 \%$, lived with a partner.

Frequency of abuse is shown in Table 1. One third of the sample $(32.8 \%)$ reported a history of CSA. Based on the CECA-Q, $94 \%$ of the cases of CSA were classified as
Table 1 Types and number of childhood abuses $(n=357)$

\begin{tabular}{lc}
\hline Type of abuses & $\mathrm{n}(\%)$ \\
\hline CSA & $117(32.8)$ \\
CPA & $196(54.9)$ \\
CVA & $87(24.4)$ \\
Number of abuses & \\
One type & \\
CSA & $105(41.7)$ \\
CPA & $28(11.1)$ \\
CVA & $59(23.5)$ \\
Two types & $18(7.1)$ \\
CSA \& CPA & $90(35.7)$ \\
CSA \& CVA & $22(8.7)$ \\
CPA \& CVA & $11(4.4)$ \\
Three types & $57(22.6)$ \\
\hline
\end{tabular}

$\mathrm{CPA}=$ child physical abuse $\mathrm{CSA}=$ child sexual abuse; $\mathrm{CVA}=$ child verbal abuse.

severe, with women reporting at least one of the following: the perpetrator was someone she knew (92.3\%), a relative $(65.8 \%)$, lived in same household $(42.7 \%)$, abused her on more than one occasion $(62.4 \%)$, touched her private parts $(74.4 \%)$, forced her to touch his (or her) private parts $(43.6 \%)$, or made her engage in sexual intercourse $(25.6 \%)$. Approximately half $(54.9 \%)$ of the women reported a history of CPA, and $24.4 \%$, a history of CVA. As to the number of abuses experienced, $41.7 \%$ experienced one, $35.7 \%$ two, and $22.6 \%$ three.

Over one-third of the sample $(37.5 \%)$ displayed significant depressive symptoms (BDI-II > 14) and $14.8 \%$ reported significant anxiety symptoms (SCL-90 > 18), while a quarter $(26.3 \%)$ reported HSB. Respondents experienced the mediating variables as follows: $27.7 \%$ lacked social support (APGAR < 20), 17.1\% had low partner adjustment (DAS < 15), and $36.7 \%$ had a history of depression (SCID).

\section{Influence of type of abuse on psychopathology}

The results of the point-biserial correlations between the variables involved are given in Table 2 . The main finding is that sociodemographic variables were not related to abuse. Table 3 shows the results of the logistic regression analyses of type of abuse (CSA, CPA, CVA) on each dependent variable separately (PDS, PAS, and HSB). The odds ratios (ORs) are reflected in column 2 for the crude models, column 3 for the adjusted models with mediating factors, and column 4 for the adjusted models with possible confounders.

\section{Prenatal depressive symptoms}

The OR for CSA remained significant in the three models, showing that women with CSA were 2.60 (crude model), 2.49 (adjusting for mediating factors), and 1.85 (adjusting for confounding factors) more likely to have PDS than women without a history of CSA. CPA had no effect on PDS in any of the models, while CVA increased the risk of PDS 1.92 times in the crude model and 2.53 times when adjusting for mediating factors. 


\section{Prenatal anxiety symptoms}

In this model, CSA and CPA remained significant. Women with a history of CSA had an OR of 2.58 (crude model), 2.13 (adjusting for mediating factors) and 2.17 (adjusting for possible confounders). For those with CPA, the risk of PAS increased 2.51, 2.44, and 2.46-fold in each model respectively.

\section{History of suicidal behavior}

Results of the logistic regression analyses for HSB (dependent variable) showed that CSA and CPA were significant in all three models. CSA increased the risk of a HSB 3.71, 3.61, and 3.68 times, respectively. CPA also

Table 2 Correlations of the abuse variables and other variables included in the regression models $(n=357)$

\begin{tabular}{lccc}
\hline & CSA & CPA & CVA \\
\hline CSA & 1 & & \\
CPA & $0.17^{*}$ & 1 & \\
CVA & $0.24^{*}$ & $0.41^{*}$ & 1 \\
PDS & $0.33^{\dagger}$ & $0.10^{\dagger}$ & $0.14^{*}$ \\
PAS & $0.27^{\dagger}$ & $0.26^{*}$ & $0.21^{\dagger}$ \\
HSB & $0.27^{*}$ & $0.20^{*}$ & $0.20^{*}$ \\
History of depression & $0.14^{*}$ & $0.12^{\dagger}$ & $0.18^{*}$ \\
Poor partner relationship & $0.15^{\dagger}$ & $0.12^{\dagger}$ & 0.08 \\
Low social support & $0.27^{\dagger}$ & $0.15^{*}$ & $0.24^{\dagger}$ \\
Marital status & 0.05 & 0.02 & 0.02 \\
Education & -0.07 & -0.03 & -0.00 \\
Income & -0.03 & -0.08 & -0.04 \\
\hline
\end{tabular}

$\mathrm{CPA}=$ child physical abuse CSA = child sexual abuse CVA = child verbal abuse; $\mathrm{HSB}=$ history of suicidal behavior; PAS = prenatal anxiety symptoms; PDS = prenatal depressive symptoms.

$* p<0.001 ; p<0.05$. increased the odds of having a HSB 2.62, 2.57 and 2.64 times, respectively. In contrast, CVA was not significantly related to HSB.

\section{Influence of number of abuses on psychopathology}

\section{Prenatal depressive symptoms}

Table 4 shows the results of the logistic regression analyses for number of abuses (CSA, CPA) on each dependent variable separately. As in the previous table, the OR is reflected in column 2 for the crude models, column 3 for the adjusted models with mediating factors, and column 4 for the adjusted models with possible confounders. The OR for PDS remained significant only when both abuses co-occurred and only in the unadjusted model and the adjusted model with possible confounders. These models showed that women who experienced three types of abuses were 3.01 (crude model) times more likely to have PDS than women without any abuse. Conversely, women who suffered one or two abuses were no more likely to have PDS than nonabused women.

\section{Prenatal anxiety symptoms}

Although experiencing one type of abuse did not increase the risk of having elevated PAS, women who experienced two and three types of abuse had an increased risk of PAS of 5.63 and 3.73 , respectively, in the crude model, with similar values for the adjusted models. The small number of women who had experienced three abuses and had PAS $(n=5)$ may explain why experiencing three types of abuse seemed to have less impact than experiencing two.

Table 3 Odds ratios $(95 \% \mathrm{Cl})$ for type of childhood abuse and prenatal depressive and anxiety symptoms and history of suicide behavior $(n=357)$

\begin{tabular}{|c|c|c|c|c|c|c|}
\hline \multirow{2}{*}{ Type of abuse } & \multicolumn{2}{|c|}{ Crude model } & \multicolumn{2}{|c|}{$\begin{array}{l}\text { Adjusted for history of depression, poor } \\
\text { partner relations, and low social support }\end{array}$} & \multicolumn{2}{|c|}{$\begin{array}{l}\text { Adjusted for marital status } \\
\text { income, and education }\end{array}$} \\
\hline & OR & $95 \% \mathrm{Cl}$ & OR & $95 \% \mathrm{Cl}$ & OR & $95 \% \mathrm{Cl}$ \\
\hline \multicolumn{7}{|l|}{ PDS (BDI-II)* } \\
\hline CSA & $2.60^{\S}$ & $1.93-4.75$ & $2.49^{\prime \prime}$ & $1.86-4.61$ & $1.85^{\prime \prime}$ & $1.38-3.69$ \\
\hline CPA & 1.10 & $0.62-1.82$ & 0.98 & $0.58-1.80$ & 0.95 & $0.56-1.61$ \\
\hline CVA & $1.92^{11}$ & $1.01-3.65$ & $2.53^{11}$ & $1.79-4.26$ & 2.50 & $1.79-4.04$ \\
\hline \multicolumn{7}{|l|}{ PAS (SCL-90) ${ }^{\dagger}$} \\
\hline CSA & $2.58^{\prime \prime}$ & $1.78-4.18$ & $2.13^{\|}$ & $1.56-4.64$ & $2.17^{\prime \prime}$ & $1.55-5.25$ \\
\hline CPA & $2.51^{11}$ & $1.15-5.44$ & $2.44^{\|}$ & $1.12-5.31$ & $2.46^{\S}$ & $1.12-5.38$ \\
\hline CVA & 1.15 & $0.73-2.20$ & 1.39 & $0.65-2.00$ & 1.39 & $0.65-2.00$ \\
\hline \multicolumn{7}{|c|}{ HSB (ideation/attempt) } \\
\hline CSA & $3.71^{\S}$ & $1.87-7.35$ & $3.61^{\S}$ & $1.81-7.20$ & $3.68^{\prime \prime}$ & $1.82-7.44$ \\
\hline CPA & $2.62^{\prime \prime}$ & $1.75-4.48$ & $2.57^{\|}$ & $1.77-4.39$ & $2.64^{\prime \prime}$ & $1.80-4.61$ \\
\hline CVA & 1.75 & $0.83-2.67$ & 1.70 & $0.80-2.70$ & 1.68 & $0.77-2.65$ \\
\hline
\end{tabular}

$95 \% \mathrm{Cl}=95 \%$ confidence interval; BDI-II = Beck Depression Inventory; CPA = child physical abuse; CSA = child sexual abuse; CVA = child verbal abuse; $\mathrm{HSB}=$ history of suicidal behavior; $\mathrm{OR}=$ odds ratio; $\mathrm{PAS}=$ prenatal anxiety symptoms; $\mathrm{PDS}=$ prenatal depressive symptoms; SCL-90 = Hopkins Symptoms Checklist.

* Crude model: $\chi^{2}=11.11, p=0.01$; first model: $\chi_{2}^{2}=25.43, p=0.00$; second model: $\chi^{2}=26.84, p=0.00$.

Crude model: $\chi_{2}^{2}=11.43, \mathrm{p}=0.01$; first model: $\chi_{2}^{2}=12.31, \mathrm{p}=0.04$; second model: $\chi_{2}^{2}=14.03, \mathrm{p}=0.01$.

${ }^{\ddagger}$ Crude model: $\chi^{2}=26.95, p=0.00$; first model: $\chi^{2}=30.19, p=0.00$; second model: $\chi^{2}=36.75 ; p=0.00$.

$\S_{p} \leqslant 0.01 ; " 11 \leqslant 0.05$. 
Table 4 Odds ratios $(95 \% \mathrm{Cl})$ for number of childhood abuses (sexual, physical, and verbal) and prenatal depressive and anxiety symptoms and history of suicide behavior $(n=357)$

\begin{tabular}{|c|c|c|c|c|c|c|}
\hline \multirow{2}{*}{ Number of abuses } & \multicolumn{2}{|c|}{ Crude model } & \multicolumn{2}{|c|}{$\begin{array}{l}\text { Adjusted for history of depression, poor } \\
\text { partner relations, and low social support }\end{array}$} & \multicolumn{2}{|c|}{$\begin{array}{l}\text { Adjusted for marital status, } \\
\text { income, and education }\end{array}$} \\
\hline & OR & $95 \% \mathrm{Cl}$ & OR & $95 \% \mathrm{Cl}$ & OR & $95 \% \mathrm{Cl}$ \\
\hline \multicolumn{7}{|l|}{ PDS (BDI-II)* } \\
\hline One type & 1.16 & $0.64-2.09$ & 1.02 & $0.55-1.88$ & 1.00 & 0.54-1.85 \\
\hline Two types & 1.82 & $0.95-2.48$ & 1.34 & $0.67-1.66$ & 1.32 & $0.66-1.68$ \\
\hline Three types & $3.01^{\S}$ & $1.36-6.64$ & 1.12 & $0.92-2.85$ & 1.12 & $0.92-1.87$ \\
\hline \multicolumn{7}{|l|}{ PAS (SCL-90) $)^{\dagger}$} \\
\hline One type & 1.52 & $0.85-1.72$ & 1.41 & $0.81-2.02$ & 1.43 & $0.81-1.79$ \\
\hline Two types & $5.63^{11}$ & $1.97-16.09$ & $5.15^{\S}$ & $1.76-15.08$ & $4.98^{\S}$ & $1.69-14.64$ \\
\hline Three types & $3.73^{\S}$ & $1.17-11.87$ & $3.28^{\S}$ & $1.09-10.80$ & $3.37^{\S}$ & $1.01-11.14$ \\
\hline \multicolumn{7}{|c|}{ HSB (ideation/attempt) } \\
\hline One type & $3.89^{\S}$ & $1.04-14.76$ & $3.77^{\S}$ & $1.00-14.11$ & 1.41 & $0.90-1.9$ \\
\hline Two types & $8.24^{\prime \prime}$ & $2.29-29.61$ & $7.43^{\S}$ & $2.03-27.24$ & $7.15^{\S}$ & $1.93-26.43$ \\
\hline Three types & $13.73^{\prime \prime}$ & $3.75-50.25$ & $13.06^{\prime \prime}$ & $3.45-49.36$ & $12.75^{\prime \prime}$ & $3.35-48.47$ \\
\hline
\end{tabular}

$95 \% \mathrm{Cl}=95 \%$ confidence interval; BDI-II = Beck Depression Inventory; HSB = history of suicidal behavior; OR = odds ratio; PAS = prenatal anxiety symptoms; PDS = prenatal depressive symptoms; SCL-90 $=$ Hopkins Symptoms Checklist.

* Crude model: $\chi^{2}=9.98, p=0.01$; first model: $\chi^{2}=24.66, p=0.00$; second model: $\chi^{2}=28.80, p=0.00$.

Crude model: $\chi^{2}=13.32, \mathrm{p}=0.00$; first model: $\chi^{2}=14.21, \mathrm{p}=0.02$; second model: $\chi^{2}=15.45, \mathrm{p}=0.04$.

* Crude model: $\chi^{2}=25.79, p=0.00$; first model: $\chi^{2}=29.12, p=0.00$; second model: $\chi^{2}=35.30, p=0.00$.

$\S p \leqslant 0.05 ; " p \leqslant 0.01$.

\section{History of suicidal behavior}

The confluence of abuse had the greatest impact on the HSB. The ORs for HSB were 3.89 in women who suffered one type of abuse, 8.24 in women who suffered two types of abuses, and 13.73 in women who suffered three types of abuses (crude model). These results were similar when adjusting for mediating and confounding variables.

\section{Discussion}

The purpose of this study was to examine the relationship between childhood sexual, physical, and verbal abuse and psychopathology (depression, anxiety, and HSB) in a sample of Mexican pregnant women at risk for depression. To our knowledge, this was the first study in this population to examine these relationships.

One of the main findings of this study is that a third of the pregnant women at risk for depression $(32.8 \%)$ had suffered CSA. Disturbingly, most $(94 \%)$ of them reported experiencing severe forms of CSA. Compared to other studies of pregnant women, the rate of CSA in this study was within the range (7-62\%) of that reported in a systematic international literature review. ${ }^{6}$ This figure is also similar to the CSA rate $(34.6 \%)$ of Mexican nonpregnant women screened for depression, ${ }^{18}$ but much higher than the CSA rate $(7.3 \%)$ of non-pregnant, notat-risk Mexican women over 14 years of age. ${ }^{36}$

CPA was found in more than half of the sample $(54.9 \%)$, and almost one-quarter (24.4\%) endorsed a history of CVA. These rates are consistent with previous studies in the United States (52\% and $27 \%$, respectively) ${ }^{9}$ but higher than those of CPA found in non-pregnant Mexican women (42.2\%). ${ }^{36}$ Overall, these data suggest that early trauma is at least as frequent among pregnant Mexican women as among women from other countries, and may be more frequent than in nonpregnant Mexican females who are not at risk of depression.
As in other studies, ${ }^{7}$ we found that CSA was associated with depressive $(O R=2.60)$ and anxiety symptoms $(O R=$ 2.58). These associations remained significant even after adjusting for mediating and confounding factors. Compared with previous research, the effect on depressive symptoms appears to be higher in this sample than that reported by Rich-Edwards et al. ${ }^{10}(\mathrm{OR}=1.23)$ and Chung et al. ${ }^{9}(\mathrm{OR}=1.94)$, possibly because of differences in the risk of depression and social disadvantages, as described below. On the other hand, CSA had the greatest impact on HSB (OR = 3.71). Farber et al. ${ }^{1}$ also found that a history of CSA was related to suicidal ideation during pregnancy and to suicide attempts before pregnancy in a sample of psychiatric obstetric patients.

Consistent with other studies, we failed to find an association between CPA and depressive symptoms, ${ }^{11,12}$ but found that women who suffered from CPA were at an increased risk of developing anxiety symptoms $(\mathrm{OR}=2.5)$, a variable not often examined in previous research. ${ }^{11}$ CPA also increased the risk of HSB $(\mathrm{OR}=2.62)$, which persisted after controlling for mediating and confounding factors. This finding is contrary to a study conducted by Farber et al., ${ }^{1}$ who did not find a significant association between physical abuse alone and a history of suicide attempts. This could be due to the fact that a smaller proportion in their sample $(8.7 \%)$ reported CPA compared to our sample (54.9\%).

CVA has been the least studied of the three types of abuse in perinatal women. Our results showed that its only effect was on PDS (OR $=1.92)$, contrary to Chung et al., ${ }^{9}$ who did not find an effect of CVA on such symptoms. In retrospect, these findings are not surprising, given that of the three types of abuse, CVA may be considered the least "severe".

Those who reported three types of abuse were more likely to experience PDS $(\mathrm{OR}=3.01)$ than those who reported one or two types. Having suffered two or three 
types of abuse (OR $=5.63$ and 3.73) increased the risk of PAS more than suffering a single type. Experiencing three types of abuse resulted in an even greater impact on HSB than each individual type of abuse, increasing the risk to 13.73 from 3.89 (when reporting one) and 8.24 (when reporting two). Similarly, studies conducted by Holzman et al. ${ }^{8}$ and Chung et al. ${ }^{9}$ found a positive link between a background involving multiple types of abuse and the risk of depressive symptoms. The confluence of the different types of abuse may result in a qualitatively different experience and impact than that derived from one type of abuse.

In summary, CSA, CPA, and CVA, especially when they co-occurred, had a significant impact on PDS, PAS, and lifetime HSB in pregnant Mexican women. ${ }^{37}$ In particular, women who experienced multiple types of abuse were more likely to report HSB. In light of this finding, it is striking that so few studies have examined HSB in pregnant women, with even fewer considering childhood abuse as a risk factor. A history of suicide attempts has been associated with significant depressive symptoms in Latino women living in the United States and in pregnant Mexican women. ${ }^{38}$ A possible explanation for this relationship is that early traumatic life experiences (such as abuse) subsequently affect how the brain responds to stressors throughout adult life, influencing the aging process and increasing susceptibility to the psychopathology, including mood and anxiety disorders. ${ }^{2}$ This connection occurs in part because the nervous system regulates and responds to systemic processes via the neuroendocrine, autonomic, and immune systems. Social factors have also been shown to have a powerful impact on brain development, structure, and function throughout the life course, thereby also affecting mental health outcomes. ${ }^{39}$

From a cultural perspective, the findings of this study decrease the likelihood of significant differences between the impact of abuse on pregnant women living in Mexico and those living in other countries. ${ }^{8-10}$ Nevertheless, cultural differences may be significant in other areas. For example, there are marked challenges in Mexico regarding access to suitable mental health services. ${ }^{40}$ From a healthcare perspective, these findings are significant because prenatal depression and anxiety have been shown to negatively affect both mother and infant health in the United States and Europe. ${ }^{13,14}$ Moreover, it has been documented that CSA and CPA are risk factors for later partner violence during pregnancy. ${ }^{37}$ Given the health consequences, there is a need for additional studies on psychopathology in pregnant women with a history of childhood abuse, particularly focusing on Latin America, to confirm the extent to which cultural differences should be considered.

Several limitations in our study should be taken into account. First, these results were based on secondary data analyses of a sample of pregnant women who participated in an RCT to evaluate an intervention to prevent postpartum depression. ${ }^{20}$ These participants were included in the study because they met the criteria for being at high risk for depression. This risk profile may have increased the rates of depressive and anxiety symptoms and HSB among this sample, thereby potentially overestimating the link between childhood abuse and mental health outcomes. This same limitation was cited in other studies of childhood abuse and psychopathology involving clinical or high-risk samples. ${ }^{41}$ However, for ethical reasons, pregnant women with a suicide attempt in the 6 months prior to the baseline interview and with other severe pathologies (major depression, bipolar disorder, substance abuse, or currently in psychological/ psychiatric treatment) were barred from participation in the RCT. Excluding these cases may have decreased the rates of depressive symptoms, anxiety symptoms, and HSB in comparison to a sample including the more severe cases. Nevertheless, there is evidence that the frequency of actual suicidal behavior in pregnant Mexican women is extremely low $(2.6$ and $0.9 \%){ }^{42}$ Second, our main outcome variables (PDS, PAS, and HSB) were measured concurrently with childhood abuse. Therefore, it is likely that women experiencing these high levels of emotional distress are more sensitive to recalling adversity. Third, the fact that questionnaires were administered in person as opposed to in a written format may have influenced women's responses, since most people have difficulty talking about their childhood abuse without first establishing proper rapport with the interviewer. ${ }^{43}$ We attempted to compensate for this limitation by using psychologists who were highly trained to create an emotionally safe environment for participants as interviewers in the study. Finally, it is important to keep in mind the limitations of data collected through retrospective childhood trauma instruments. ${ }^{44}$ As previously noted, the description of events may be biased, affecting estimates of abuse prevalence and their link with clinical variables. Recollection may also vary at different developmental stages: very early trauma events (those occurring prior to 6 years of age) may not be recalled as frequently or accurately as those occurring at later stages, leading to nonsystematic underreporting and a greater possibility of distortion.

The results of this study add to the small but growing body of research on perinatal psychopathology in women in developing countries, particularly Latin America. Further research is required to determine the scope of these findings in the region, particularly in regard to the effects of childhood maltreatment on suicidality before and during pregnancy. The fact that a high number of pregnant women reported untreated symptoms of depression and anxiety, a history of suicidality, and sexual and physical abuse suggests the need for more comprehensive screening in prenatal care. Such screening, coupled with feasible, cost-effective interventions - which have yet to be developed - would help reduce negative consequences for the mother and their effect on the child. Educating perinatal women and health care providers about major risk factors for depression, anxiety, and suicidality during pregnancy is an essential starting point to promote the mental health of mothers and infants.

\section{Acknowledgements}

This study was supported by Consejo Nacional de Ciencia y Tecnología (CONACyT, Salud-2003-C01.021). We are grateful to Centro de Salud José Castro Villagrana, Hospital de Especialidades de la Mujer de la 
SEDENA, and Instituto Nacional de Perinatología Isidro Espinosa de los Reyes. Thanks are also due to research team members Cecilia Mattei, Teresa García Hubard, Claudia Navarro, Gabriela Letechipía, Erika Trujillo, Yazmín Quintero, Sofía Arce, Alejandra Guerrero, Araceli Aguilar, and Brenda Jiménez; and to Nicole DeSario Hedrick for her assistance in manuscript edits.

\section{Disclosure}

The authors report no conflicts of interest.

\section{References}

1 Farber EW, Herbert SE, Reviere SL. Childhood abuse and suicidality in obstetrics patients in an hospital-based urban prenatal clinic. Gen Hosp Psychiatry. 1996;18:56-60.

2 Hassel S, McKinnon MC, Cusi AM, MacQueen GM. An overview of psychological and neurobiological mechanisms by which early negative experiences increase risk of mood disorders. J Can Acad Child Adolesc Psychiatry. 2011;20:277-88.

3 Carr CP, Martins CM, Stingel AM, Lemgruber VB, Juruena MF. The role of early life stress in adult psychiatric disorders: a systematic review according to childhood trauma subtypes. J Nerv Ment Dis. 2013;201:1007-20.

4 Grassi-Oliveira R, Ashy M, Stein LM. Psychobiology of childhood maltreatment: effects of allostatic load? Rev Bras Psiquiatr. 2008;30:60-8.

5 Lang AJ, Rodgers CS, Lebeck MM. Associations between maternal childhood maltreatment and psychopathology and aggression during pregnancy and postpartum. Child Abuse Negl. 2006;30:17-25.

6 Leeners B, Richter-Appelt H, Imthurn B, Rath W. Influence of childhood sexual abuse on pregnancy, delivery, and the early postpartum period in adult women. J Psychosom Res. 2006;61:139-51.

7 Leeners B, Rath W, Block E, Görres G, Tschudin S. Risk factors for unfavorable pregnancy outcome in women with adverse childhood experiences. J Perinat Med. 2014;42:171-8.

8 Holzman C, Eyster J, Tiedje LB, Roman LA, Seagull E, Rahbar MH. A life course perspective on depressive symptoms in mid-pregnancy. Matern Child Health J. 2006;10:127-38.

9 Chung EK, Mathew L, Elo IT, Coyne JC, Culhane JF. Depressive symptoms in disadvantaged women receiving prenatal care: the influence of adverse and positive childhood experiences. Ambul Pediatr. 2008;8:109-16.

10 Rich-Edwards JW, James-Todd T, Mohllajee A, Kleinman K, Burke A, Gillman MW, et al. Lifetime maternal experiences of abuse and risk of pre-natal depression in two demographically distinct populations in Boston. Int J Epidemiol. 2011;40:375-84.

11 Edwards B, Galletly C, Semmler-Booth T, Dekker G. Antenatal psychosocial risk factors and depression among women living in socioeconomically disadvantaged suburbs in Adelaide, South Australia. Aust N Z J Psychiatry. 2008:42:45-50.

12 Dayan J, Creveuil C, Dreyfus M, Herlicoviez M, Baleyte JM, O'Keane V. Developmental model of depression applied to prenatal depression: role of present and past life events, past emotional disorders and pregnancy stress. PLoS One. 2010;5:e12942.

13 Bennett HA, Einarson A, Taddio A, Koren G, Einarson TR. Prevalence of depression during pregnancy: systematic review. Obstet Gynecol. 2004;103:698-709.

14 Ross LE, McLean LM. Anxiety disorders during pregnancy and the postpartum period: A systematic review. J Clin Psychiatry. 2006;67:1285-98.

15 Gandhi SG, Gilbert WM, McElvy SS, Kady D, Danielson B, Xing G, et al. Maternal and neonatal outcomes after attempted suicide. Obstet Gynecol. 2006;107:984-90.

16 Ocampo R, Heinze G, Ontiveros MP. Detección de depresión postparto en el Instituto Nacional de Perinatología. Psiquiatría. 2007;23: 18-22.

17 Melo EF Jr, Cecatti JG, Pacagnella RC, Leite DF, Vulcani DE, Makuch MY. The prevalence of perinatal depression and its associated factors in two different settings in Brazil. J Affect Disord. 2012;136:1204-8.
18 Navarrete L, Navarro C, Lara MA. Abuso sexual en la infancia en mujeres con sintomatología depresiva. Psiquiatría. 2007;23:8-12.

19 Lancaster CA, Gold KJ, Flynn HA, Yoo H, Marcus SM, Davis MM. Risk factors for depressive symptoms during pregnancy: a systematic review. Am J Obstet Gynecol. 2010;202:5-14.

20 Lara MA, Navarro C, Navarrete L. Outcome results of a psychoeducational intervention in pregnancy to prevent PPD: a randomized control trial. J Affect Disord. 2010;122:109-17.

21 Radloff LS. The CES-D scale: a self-report depression scale for research in the general population. Appl Psychol Meas. 1977;1:385-401.

22 Bifulco A, Bernazzani O, Moran PM, Jacobs C. The childhood experience of care and abuse questionnaire (CECA.Q): validation in a community series. Br J Clin Psychol. 2005;44:563-81.

23 Bellis MA, Hughes K, Leckenby N, Perkins C, Lowey H. National household survey of adverse childhood experiences and their relationship with resilience to health-harming behaviors in England. BMC Med. 2014;12:72.

24 Yeoman K, Safranek T, Buss B, Cadwell BL, Mannino D. Adverse childhood experiences and adult smoking, Nebraska, 2011. Prev Chronic Dis. 2013;10:E159.

25 Beck A, Steer R, Brown G. Manual for Beck Depression Inventory. San Antonio: Psychological Corporation; 1996.

26 Jurado S, Villegas ME, Méndez L, Rodríguez F, Loperena V, Varela R. La estandarización del inventario de depresión de Beck para los residentes de la ciudad de México. Salud Ment. 1998;21:26-31.

27 First MB, Spitzer RL, Gibbon M, Williams JB. Structured Clinical Interview for DSM-IV Axis I Disorders, Clinician Version (SCID-CV). Washington: American Psychiatric Press; 1996.

28 Derogatis LR. Administration, Scoring and Procedures Manual-I for the Revised Version SCL-90R. Baltimore: Johns Hopkins; 1977.

29 Lara MC, Espinosa SI, Cárdenas ML, Fócil M, Cavazos J. Confiabilidad y validez de la SCL-90 en la evaluación de psicopatología en mujeres. Salud Ment. 2005;28:42-50.

30 Medina-Mora ME, Rascón ML, Tapia R, Mariño MC, Juárez F, Villatoro J, et al. Trastornos emocionales en población urbana mexicana: resultados de un estudio nacional. An Inst Mex Psiquiatr. 1992;3:48-55.

31 Gonzalez C, Villatoro J, Alcántar I, Medina ME, Fleiz C, Bermudez P, et al. Prevalencia de intento suicida en estudiantes adolescentes de la ciudad de México: 1997 y 2000. Salud Ment. 2002;25:1-12.

32 Norwood SL. The Social Support Apgar: instrument development and testing. Res Nurs Health. 1996;19:143-52.

33 Diaz MA, Le HN, Cooper BA, Muñoz RF. Interpersonal factors and perinatal depressive symptomatology in a low-income Latina sample. Cultur Divers Ethnic Minor Psychol. 2007;13:328-36.

34 Spanier GB. Measuring dyadic adjustment: new scales of assessing the quality of marriage and similar dyads. J Marriage Fam. 1976;38:15-28.

35 Sharpley CF, Cross DG. A psychometric evaluation of the Spanier Dyadic Adjustment Scale. J Marriage Fam. 1982;44:739-42.

36 Rivera-Rivera L, Allen B, Chávez-Ayala R, Avila-Burgos L. Abuso físico y sexual durante la niñez y revictimización de las mujeres mexicanas durante la edad adulta. Salud Publica Mex. 2006;48:268-78.

37 Cuevas S, Blanco J, Juarez C, Palma O, Valdez-Santiago R. Violencia y embarazo en usuarios del sector salud en estados de alta marginación en México. Salud Publica Mex. 2006;48:239-49.

38 Lara MA, Le HN, Letechipia G. Hochhausen L. Prenatal depression in Latinas in the U.S. and Mexico. Matern Child Health J. 2009;13:567-76.

$39 \mathrm{McE} w e n$ BS. Physiology and neurobiology of stress and adaptation: central role of the brain. Physiol Rev. 2007;87:873-904.

40 Borges G, Medina-Mora ME, Wang PS, Lara C, Berglund P, Walters $\mathrm{E}$. Treatment and adequacy of treatment for mental disorder among respondents to the Mexico National Comorbidity Survey. Am J Psychiatry. 2006;163:1371-8.

41 Lacelle C, Hébert M, Lavoie F, Vitaro F, Tremblay RE. Sexual health in women reporting a history of child sexual abuse. Child Abuse Negl. 2012;36:247-59.

42 Lara MA, Letechipia G. Ideación y comportamiento suicida en embarazadas. Salud Ment. 2009;32:381-7.

43 Goldman JD, Padayachi UK. Some methodological problems in estimating incidence and prevalence in child sexual abuse research. J Sex Res. 2000;37:305-14.

44 Roy CA, Perry JC. Instruments for the assessment of childhood trauma in adults. J Nerv Ment Dis. 2004;192:343-51. 